\title{
Caracterização dos casos de violência doméstica contra a mulher atendidos em dois hospitais públicos do Rio de Janeiro
}

\author{
Characterization of the cases of domestic violence \\ against women assisted in two public hospitals \\ of Rio Janeiro
}

Suely F. Deslandes 1

Romeu Gomes 1

Cosme Marcelo Furtado Passos da Silva 2

\footnotetext{
1 Departamento de Ensino, Instituto Fernandes Figueira, Fundação Oswaldo Cruz. Av. Rui Barbosa 716,

Flamengo, Rio de Janeiro, $R J$ 22250-020, Brasil. desland@iff.fiocruz.br romeu@iff.fiocruz.br

2 Centro Latino-Americano de Estudos de Violência e Saúde Jorge Careli, Departamento de Epidemiologia e Métodos Quantitativos em Saúde, Escola Nacional de Saúde Pública, Fundação Oswaldo Cruz. Av. Brasil 4036, sala 702, Manguinhos, Rio de Janeiro, $R J$ 21040-361, Brasil. passos@manguinhos.ensp.fio cruz.br

cfpassos@rio.nutecnet.com.br
}

\begin{abstract}
This paper aims at: (a) to analyze the distribution of the cases of domestic violence against women (adolescent and adult) in relation to emergency care due to external causes; (b) to characterize the victims and the rendered care; (c) to analyze the circumstances in which events happened. In methodological terms, it tries to articulate the quantitative and qualitative approaches. The study was developed in two public hospitals of reference placed in the city of Rio de Janeiro. Of the 72 assisted women, most referred to the husband, the partner or the boyfriend as the aggressor (69,4\%) and were beaten (70.4\%), especially on the face and on the head. The study cames to the conclusion that the health services should provide a good clinical care and promote prevention's actions.
\end{abstract}

Key words Battered Women; Domestic Violence; Emergency Medical Services

Resumo O artigo objetiva: (a) analisar a distribuição dos casos de violência doméstica contra a mulher (adolescente e adulta) em relação ao atendimento emergencial por causas externas; (b) caracterizar as vítimas e o atendimento prestado; (c) analisar as circunstâncias em que ocorreram esses eventos. Procurou-se articular as abordagens quantitativas e qualitativas. O estudo foi desenvolvido em dois hospitais públicos de referência situados no Município do Rio de Janeiro. Das 72 mulheres atendidas, a maioria referiu como agressor o esposo/companheiro/namorado $(69,4 \%)$ e sofreu agressões por espancamento $(70,4 \%)$, sobretudo na região de face e cabeça. Conclui-se que o atendimento emergencial deve prestar uma atenção clínica e cirúrgica de qualidade, mas também ser capaz de desencadear ações preventivas.

Palavras-chave Mulheres Maltratadas; Violência Doméstica; Serviços Médicos de Emergência 


\section{Introdução}

O presente artigo constitui parte de uma pesquisa que teve como objeto de análise o impacto das causas externas no atendimento de emergência hospitalar. Este estudo analisou todos os casos de violências e acidentes atendidos nos meses de maio (Hospital Municipal Miguel Couto) e junho (Hospital Municipal Salgado Filho) de 1996, segundo as causas específicas, a caracterização das vítimas e o atendimento dispensado (Deslandes, 1997).

Este artigo, de caráter descritivo, objetiva: a) analisar a distribuição dos casos de violência doméstica contra a mulher (adolescente e adulta) em relação ao atendimento emergencial; b) caracterizar as vítimas e o atendimento prestado; c) analisar, quantitativa e qualitativamente, as circunstâncias e as relações que contextualizam esses eventos.

Para Boulding (1981), a mulher é quem mais sofre, tanto a violência de comportamento como a violência estrutural, em virtude das definições sociais que lhe atribuem um papel secundário, limitando a sua cidadania em todos os níveis de hierarquia social.

Como ressalta Giffin (1994), a família é uma instituição social que organiza as relações sexuais entre gêneros, exercendo de forma direta um controle social sobre a identidade e sobre o corpo da mulher. Tal controle pode legitimar direitos dos maridos sobre suas esposas, dando-lhes prerrogativa de exercerem até mesmo a força física contra elas.

Contudo, Boulding (1981) também chama a atenção para o fato de a mulher internalizar e reproduzir a agressão, contribuindo para que as estruturas que a transformam em vítima sejam mantidas. Nesse cenário, destacam-se os casos de mães que colaboram ativamente no "endurecimento" de seus filhos, transformando-os em "machos agressivos".

No cenário da violência contra a mulher, a violência doméstica ou familiar assume um papel de destaque. Saffioti (1997), com base em dados da Pesquisa Nacional por Amostra de Domicílios de 1990, do IBGE (Instituto Brasileiro de Geografia e Estatística), observa que, dentre todas as agressões físicas cometidas no âmbito da residência, $63 \%$ das vítimas foram mulheres.

Azevedo \& Guerra (1989) concebem a violência doméstica a partir de conflitos de gerações (contra crianças e adolescentes) e de gênero (violência contra a mulher). Esses conflitos, para as autoras, são produtos da dificuldade de se lidar com as diferenças. Neste trabalho, entende-se violência doméstica como as variadas formas de violência interpessoal (agressão física, abuso sexual, abuso psicológico e negligência) que ocorrem dentro da família, sendo perpetradas por um agressor (que possui laços de parentesco, familiares ou conjugais) em condições de superioridade (física, etária, social, psíquica e/ou hierárquica) (MS, 1993).

Segundo Heise et al. (1994), a violência presente nas relações de gênero é um sério problema de saúde para mulheres em todo mundo. Do ponto de vista desses autores, embora esse tipo de violência seja uma causa significativa de morbidade e mortalidade de mulheres, quase nunca é visto como uma questão de saúde pública. Os autores, assinalando a extensão dessa problemática, citam a estimativa do Banco Mundial para 1993 de que, no conjunto dos indicadores de doença dos países desenvolvidos e em desenvolvimento, a violência presente nas relações de gênero representa um entre cada cinco dias de vida perdidos para mulheres em idade reprodutiva. A violência doméstica e o estupro seriam a sexta causa de anos de vida perdidos por morte ou incapacidade física em mulheres de 15 a 44 anos - mais que todos os tipos de câncer, acidentes de trânsito e guerras.

Os reflexos desse problema são nitidamente percebidos no âmbito dos serviços de saúde, seja pelos custos que representam, seja pela complexidade do atendimento que demandam. Heise et al. (1994) citam um estudo americano da Health Maintenance Organization (HMO), afirmando que as mulheres abusadas sexualmente ou espancadas representaram, para o sistema de saúde, em um ano de acompanhamento, custos 2,5 maiores que as mulheres que não foram vitimadas.

\section{Material e métodos}

Em termos de princípios metodológicos, a investigação da qual faz parte este trabalho procurou articular as abordagens quantitativa e qualitativa (Minayo \& Sanches, 1993), pretendendo contemplar: a) a dimensão do significado e da intencionalidade presentes nos atos, nas relações e nas estruturas sociais conforme propõe Minayo (1992); b) a caracterização epidemiológica em nível descritivo.

O estudo foi desenvolvido em dois hospitais públicos: Hospital Municipal Miguel Couto (HMMC) e Hospital Municipal Salgado Filho (HMSF). Estes hospitais foram selecionados por serem referência de atendimento de emergência em duas áreas distintas da cidade, o HMMC, 
situado na zona sul (área mais rica), e o HMSF, situado na zona norte (área de subúrbio).

Efetuou-se, inicialmente, um censo do atendimento emergencial de todas as vítimas por causas externas (Deslandes, 1997), das quais serão analisados, neste artigo, os dados acerca das mulheres adolescentes e adultas (com idade igual ou superior a 15 anos) vítimas de violência doméstica, cujo agressor foi do sexo masculino (cônjuges, ex-cônjuges, parceiros sexuais e parentes). Assim, para efeito de análise, aqui será considerada a violência doméstica especificamente voltada contra a mulher, no cenário das relações de gênero.

A coleta dos dados transcorreu durante os meses de maio no HMMC e de junho no HMSF no ano de 1996. Os referidos meses foram escolhidos por serem considerados típicos na rotina desses hospitais. Este desenho de pesquisa possibilita tão somente uma perspectiva pontual desta realidade. Contudo, permite uma análise das características destas vítimas e do atendimento que demandaram, bem como das relações entre vítima e agressor, dados que podem ser considerados raros e dificilmente disponíveis.

No Hospital Municipal Miguel Couto, em maio de 1996, foram socorridas 2.736 pessoas por acidentes ou violências, sendo que destas, 45 foram vítimas de violência doméstica, das quais $29(64,4 \%)$ eram do sexo feminino. Destas, 24 tinham 15 ou mais anos de idade. Ao se analisarem os relatos e circunstância do abuso, três casos foram excluídos, pois em dois deles o agressor era a própria mãe, e, no terceiro, o agressor era uma irmã. Assim, neste hospital, nossa população referiu-se a 21 casos.

Em junho do mesmo ano, no Hospital Municipal Salgado Filho foram atendidas 2.415 vítimas de causas externas, sendo que 90 casos corresponderam à violência doméstica. Destes casos, em $56(62,2 \%)$ atendimentos a vítima foi do sexo feminino e 54 encontravam-se na faixa de 15 ou mais anos. Foram excluídos três casos em que o agressor era uma irmã, perfazendo um total de 51 casos neste hospital.

Cada vítima atendida por este motivo correspondeu a um questionário preenchido pela equipe de pesquisa. Esse instrumento, em geral, abrangeu os seguintes aspectos: dados sócio-demográficos da vítima, tipo e características do evento, tipo de atendimento prestado. Os auxiliares de pesquisa, dispostos em plantões, durante 24 horas por dia, aplicavam o questionário diretamente à paciente quando de sua entrada no atendimento. Quando esta não apresentava condições, as respostas foram fornecidas pelo socorrista e/ou acompanhan- te. Este método mostrou-se eficaz, uma vez que, de todos os casos de causas externas, em apenas $0,5 \%$ dos casos do Miguel Couto e $0,3 \%$ dos casos estudados no Salgado Filho não foi possível se detectar a causa básica do agravo violento.

Torna-se fundamental indicar que a classificação das causas foram aferidas segundo as declarações da paciente ou, na impossibilidade desta, nas do socorrista ou acompanhante, e era absolutamente impossível checar a veracidade das informações prestadas. Este fato é de grande relevância para a questão da violência doméstica, tendo ocorrido, provavelmente, um grande nível de subnotificação, pois é sabido que muitas mulheres declaram outra história (acidentes), visando encobrir a situação ou até mesmo proteger o agressor (Heise et al., 1994; Hartigan, 1997).

Os pesquisadores acompanharam o paciente desde sua admissão no setor de emergência até o término do atendimento, seja por alta médica, transferência para outros setores do próprio hospital fora da emergência, transferência para outro hospital, saída à revelia ou óbito do paciente. As informações relativas ao atendimento prestado foram aferidas pela equipe da pesquisa com base na observação de campo.

A partir dessas fichas foi montado um banco de dados em Dbase III Plus, trabalhando-se com freqüências simples e percentual através do programa Epi-Info 6.0. Após a integralização desse banco, foram realizados cruzamentos de variáveis, através do mencionado programa.

Foram considerados também breves relatos das vítimas sobre os motivos e circunstâncias da agressão. Estes dados qualitativos foram analisados através da Técnica de Análise Temática que "consiste em descobrir os 'núcleos de sentido' que compõem a comunicação e cuja presença, ou freqüência de aparição podem significar alguma coisa para o objetivo analítico escolhido" (Bardin, 1979:105). Além de se buscar respostas para questões, com esta técnica, pode-se caminhar na direção da "descoberta do que está por trás dos conteúdos manifestos, indo além das aparências do que está sendo analisado" (Gomes, 1994:74). 


\section{Apresentação e discussão dos resultados}

\section{Caracterização das vítimas}

Conforme pode ser visto na Tabela 1 , das 72 mulheres atendidas nos dois hospitais, predominou a faixa etária de 20 a 29 anos $(45,7 \%$ - 32 casos), seguida pelas faixas de 30 a $39(28,6 \%$ 20 casos) e das adolescentes de 15 a 19 anos (11,4\% - 8 casos). Esses dados, referentes a um universo tão restrito, estão de acordo com as características da população em geral. Saffioti (1997), com base em dados do IBGE de 1990, observa que a maior incidência de agressões fí- sicas cometidas contra a mulher se situa nas faixas etárias de 18 a 29 anos, com 28,7\%, e 30 e 40 anos, com $25,3 \%$.

Quanto ao estado civil, das mulheres atendidas nos dois hospitais, a maioria declarou-se solteira $(45,7 \%)$, seguida pelas casadas $(35,7 \%)$. Como esta classificação baseou-se no relato espontâneo, muitas que convivem com um companheiro declararam-se como solteiras.

A renda familiar esteve predominantemente na faixa de um a três salários mínimos $(42,6 \%)$, seguida pela faixa de quatro a seis salários $(36,1 \%)$. Comparando-se o conjunto de todos os atendimentos por causas externas com o grupo das mulheres vítimas de violência

Tabela 1

Características sócio-demográficas das mulheres estudadas. HMMC* (maio de 1996) e HMSF** (junho de 1996).

\begin{tabular}{|c|c|c|c|c|c|c|}
\hline \multirow{2}{*}{$\begin{array}{l}\text { Características } \\
\text { sócio-demográficas }\end{array}$} & \multicolumn{2}{|c|}{ HMMC } & \multicolumn{2}{|c|}{ HMSF } & \multicolumn{2}{|c|}{ Total } \\
\hline & $\mathrm{n}$ & $\%$ & $n$ & $\%$ & $n$ & $\%$ \\
\hline Faixa etária & 21 & 100,0 & 49 & 100,0 & 70 & 100,0 \\
\hline $15-19$ & 3 & 14,3 & 5 & 10,2 & 8 & 11,4 \\
\hline $20-29$ & 9 & 42,9 & 23 & 47,0 & 32 & 45,7 \\
\hline $30-39$ & 5 & 23,8 & 15 & 30,6 & 20 & 28,6 \\
\hline $40-49$ & 2 & 9,5 & 4 & 8,2 & 6 & 8,6 \\
\hline $50-59$ & 2 & 9,5 & 1 & 2,0 & 3 & 4,3 \\
\hline 60 ou mais & - & - & 1 & 2,0 & 1 & 1,4 \\
\hline Renda familiar & 18 & 100,0 & 43 & 100,0 & 61 & 100,0 \\
\hline < 1 salário mínimo & - & - & 3 & 7,0 & 3 & 4,9 \\
\hline 1 a 3 salários mínimos & 9 & 50,0 & 17 & 39,5 & 26 & 42,6 \\
\hline 4 a 6 salários mínimos & 6 & 33,3 & 16 & 37,2 & 22 & 36,1 \\
\hline > 6 salários mínimos & 3 & 16,7 & 7 & 16,3 & 10 & 16,4 \\
\hline Estado civil & 21 & 100,0 & 49 & 100,0 & 70 & 100,0 \\
\hline Casada & 7 & 33,3 & 18 & 36,7 & 25 & 35,7 \\
\hline Solteira & 10 & 47,7 & 22 & 45,0 & 32 & 45,7 \\
\hline Separada & 2 & 9,5 & 8 & 16,3 & 10 & 14,3 \\
\hline Outros & 2 & 9,5 & 1 & 2,0 & 3 & 4,3 \\
\hline Ocupação & 17 & 100,0 & 39 & 100,0 & 56 & 100,0 \\
\hline Profissão de nível superior & 1 & 5,9 & 3 & 7,7 & 4 & 7,1 \\
\hline Profissão de nível técnico & 1 & 5,9 & 1 & 2,6 & 2 & 3,6 \\
\hline Comércio & 3 & 17,6 & 3 & 7,7 & 6 & 10,7 \\
\hline Setor de serviços & 5 & 29,5 & 5 & 12,8 & 10 & 17,9 \\
\hline Funcionalismo e segurança pública & - & - & 2 & 5,1 & 2 & 3,6 \\
\hline Estudantes & 3 & 17,6 & - & - & 3 & 5,3 \\
\hline Setor administrativo & - & - & 2 & 5,1 & 2 & 3,6 \\
\hline Do lar & - & - & 9 & 23,1 & 9 & 16,1 \\
\hline Desempregada & 3 & 17,6 & 10 & 25,6 & 13 & 23,2 \\
\hline Economia informal & 1 & 5,9 & 4 & 10,3 & 5 & 8,9 \\
\hline
\end{tabular}

Obs: Exclui ignorados.

* Hospital Municipal Miguel Couto.

** Hospital Municipal Salgado Filho. 
doméstica, percebe-se que essas mulheres apresentaram um nível de estratificação de renda um pouco mais alto, com percentuais maiores na faixa de quatro a seis salários. Observase que o ideal seria obter os dados sobre a renda familiar per capita, uma vez que as famílias numerosas, com maior número de dependentes, teria um nível de pobreza mais acentuado.

Quanto à ocupação atual, as mulheres desempregadas predominaram $(23,2 \%)$, seguidas das que trabalham no setor de serviços $(17,9 \%)$ e daquelas que não trabalham ("do lar"), com $16,1 \%$. Considerando-se as desempregadas e as "do lar", obtém-se a maioria de $39,3 \%$, que depende economicamente de outra pessoa. Neste item houve variação significativa entre o grupo de mulheres atendidas nos dois hospitais. No Miguel Couto predominou a ocupação no setor de serviços $(29,4 \%)$, seguida das comerciárias, estudantes e desempregadas (todas com 17,6\%). No Salgado Filho, as desempregadas representaram $25,6 \%$ e as "do lar" $23,1 \%$, seguidas das que trabalham no setor de serviços $(12,8 \%)$. Em termos comparativos, as mulheres atendidas na zona norte são mais dependentes quanto ao seu sustento $(48,7 \%)$.

Segundo Relatório Anual Totalizador das Delegacias Especiais de Atendimento à Mulher do Estado do Rio de Janeiro (Soares et al., 1996), das 6.640 denúncias feitas no ano de 1992, 47\% das vítimas não possuíam renda própria.

\section{Circunstâncias e contexto da agressão:} análise dos dados e dos relatos

A absoluta maioria das agressões foi praticada no interior da residência (83,3\%). Este dado também é encontrado na literatura (Giffen, 1994; Soares et al., 1996), sendo prática recorrente, facilitada pelo fato de a agressão transcorrer sem interrupções de outras pessoas e sob a legitimidade da privacidade do lar.

O marido foi o agressor na grande maioria dos casos (41 casos, 56,9\%). Observou-se também a presença de ex-maridos em cinco casos $(6,9 \%)$, de namorados em três casos $(4,2 \%)$ e ex-namorado em um caso $(1,4 \%)$. Este conjunto, que será designado como uma relação conjugal, foi responsável por $69,4 \%$ dos agressores (cinqüenta casos). Das oito adolescentes atendidas, cinco foram agredidas por alguém que tinha uma relação conjugal e três foram atingidas por parentes.

Segundo o relatório Injustiça Criminal - A Violência Contra a Mulher no Brasil, do America's Watch, em quase todas as agressões domésticas, o marido ou amante foi o responsável pela agressão (Cardoso, 1996). Soares et al. (1996), estudando 521 denúncias em Delegacias Especiais de Atendimento à Mulher (DEAMs), também encontraram que $77,6 \%$ dos agressores pertenciam ao grupo de maridos, companheiros, ex-maridos e ex-companheiros. Rodriguez \& Guerra (1996) realizaram um estudo randomizado, no período de 1994-1995, na cidade de Guadalajara, México, com 57 mulheres. Foi observado que, desse conjunto, 26 mulheres sofriam violência doméstica (46\%) e, destas, 19 (73\%) tiveram como agressor o esposo.

Outros familiares também foram, em menor escala (22 casos, 30,6\%), responsáveis pela agressão: sete casos de irmão $(9,7 \%)$, dois casos de filho $(2,8 \%)$, um caso de pai $(1,4 \%), 12$ casos de parentes $(16,7 \%)$ - três primos, três cunhados, um tio, um genro e quatro parentes não especificados. O estudo de Soares et al. (1996) apontou que 9,4\% dos agressores, na referida pesquisa, eram parentes.

Importa ressaltar que, nestes casos de agressões por parentes, a absoluta maioria das vítimas era de mulheres adultas, descaracterizando o quadro de violência doméstica contra criança e adolescente.

Os relatos aqui analisados foram feitos espontaneamente pelas mulheres. Em apenas cinco dos 72 casos, percebeu-se um certo temor ou constrangimento em contar o acontecido. Naturalmente, a forma de apresentação dos pesquisadores colaborou para tal prova de confiança, o que poderia não ocorrer caso o entrevistador fosse um policial. Contudo, ainda que considerando-se o fato de que estes são os casos declarados e que, provavelmente, houve um considerável contingente não declarado, percebeu-se nas vítimas uma grande vontade de falar para alguém, de "desabafar". Estas mulheres, em sua grande maioria, chegavam muito nervosas e chorando. Este quadro não permite deduzir que tais mulheres, caso fosse dada a oportunidade, dariam queixa policial contra seu agressor. Dos 72 casos, apenas três mulheres relataram explicitamente que iriam dar queixa (o que não quer dizer que outras não deram nem que estas referidas mulheres prosseguiram com tal intento). Destas três mulheres, uma foi agredida pelo irmão.

Nos serviços de saúde é sabido que a mulher vitimada que busca socorro médico sente muita vergonha e medo de revelar a origem de suas lesões (Hartigan, 1997; Tuesta, 1997). Editorial do Hospital Medicine afirma que das mulheres atendidas nas emergências por acidentes, se forem abordadas de forma sensível pelos profissionais de saúde, cerca de $35 \%$ delas acabam por declarar que foram vítimas de violência (Friend, 1998). 
Analisando-se a geografia das lesões, ou seja, quais partes do corpo foram atingidas pelo agressor (em cada caso podem ter sido lesionadas mais de uma parte do corpo), verificou-se que a face e a cabeça (22 e cinco eventos, respectivamente) foram as áreas corporais mais atingidas, seguidas por braço e mão (oito e 13 eventos, respectivamente), corpo inteiro (dez eventos), região do tronco (tórax em quatro eventos, costas em dois e abdômen em três) e, por fim, os membros inferiores (perna em quatro eventos e pé em dois). Percebe-se que a face é a área preferida pelos agressores, tendo sido constantes os relatos de socos no olho e mandíbula, sendo mais raramente referidos casos de chutes. Segundo os relatos, nos casos em que o braço ou mão foi atingida, na maioria das vezes foi porque a mulher tentou proteger a face de um golpe desferido, funcionando assim como anteparo e sofrendo o impacto da agressão. Os casos de múltiplas partes atingidas (corpo inteiro) referem-se a lesões sofridas por socos e, na maioria das vezes, por chutes. A região do tronco foi mais atingida por algum instrumento, faca ou por chutes.

Cardoso (1996), com base no relatório do America's Watch - Projeto dos Direitos Humanos das Mulheres -, de 1992, que aborda a violência contra a mulher no Brasil, observa que mais de $40 \%$ das agressões contra mulher registradas envolvem golpes, bofetadas, amarração, pancadas, queimadura dos seios e da genitália e estrangulamento. Tais dados, que apontam a gravidade das lesões, indicam uma possível explicação para o fato de mulheres vitimadas que não recebem o apoio de ações preventivas demandarem mais atendimentos de emergência, hospitalização e atendimentos ambulatoriais do que as mulheres que não são vítimas de violência (Dearwater et al., 1998).

Analisando-se o conjunto dos casos, percebeu-se que o espancamento (emprego da força física sem auxílio de instrumentos) foi a forma utilizada pelos agressores em 70,4\% dos casos, seguido de agressão com instrumento (pau, cabo de vassoura, barra de ferro) em $21,1 \%$ e o uso de arma branca em dois casos, arma de fogo em um caso e atropelamento intencional em um caso.

O presente estudo também analisou os relatos espontâneos das vítimas. Tais dados são fundamentais para a compreensão das circunstâncias e motivos atribuídos para as agressões.

Dada a gravidade e circunstâncias do relato, pode-se supor que, em cinco dos 51 casos atendidos no HMSF, a agressão configurou uma tentativa de homicídio. No HMMC, dois dos 21 casos possuíam características que permitem tal suposição (o que não quer dizer que os outros casos não fossem de extrema gravidade ou, mesmo, não constituíssem tal tentativa). Em um único caso, uma mulher relatou ter tentado suicídio por causa da situação de violência sofrida, ingerindo 12 comprimidos de Lexotan e vários outros de Tegretol. Dessas situações que envolveram gravidade indiscutível, destacam-se os seguintes relatos:

\section{- Relato 1 - HMSF - Adolescente de 18 anos}

"Paciente relata que brigou com o namorado e este, então, a empurrou contra um ônibus, fazendo com que ela fosse atropelada (sua face foi atingida)".

\section{- Relato 2 - HMSF - Mulher de 38 anos}

"Paciente relata que mora com um companheiro alcoólatra, que havia bebido muito e tentou bater nela. Ela o afastou e estava sentada no sofá vendo TV. Ele veio com uma faca e enfiou no seu abdômen."

\section{- Relato 3 - HMMC - Mulher de 30 anos}

"Paciente grávida de oito meses relata que foi agredida pelo marido com um pedaço de pau na barriga e no rosto(...)".

Em um dos casos, embora não fosse evidente a tentativa de homicídio, ficou explícita a aplicação de agressão com requintes de crueldade:

\section{- Relato 4 - HMSF - Mulher de 40 anos}

"Relata que, como o seu marido não dormiu em casa, ela foi no trabalho dele para tirar satisfação, e ele começou a discutir com ela e a agrediu com uma barra de ferro e jogou cola em cima de seu corpo".

Nos relatos que narram como se desencadeou a agressão, tratando-se de uma relação conjugal, observou-se, basicamente, três situações possíveis: a) marido e mulher discutem e, no calor das agressões verbais, ele a agride fisicamente; b) o marido chega alcoolizado, xingando a mulher e a agride, com ou sem prévia discussão; c) mutuamente homem e mulher se agridem corporalmente, o marido revida com maior intensidade ou inicia espancamento da mulher.

\section{- Relato 5 - HMSF - Mulher de 31 anos}

"Paciente relata que estava em casa, começou a discutir com o marido, pois ele estava debochando do seu filho mais velho. Falava que não 
gostava dela nem deste filho, que só gostava do filho mais novo. Ela ficou nervosa, começou a discutir, aí ele veio para cima dela, deu-lhe um soco, pegou uma garrafa e cortou a sua mão".

\section{- Relato 6-HMSF - Mulher de 29 anos}

"A paciente relata que o marido chegou em casa embriagado, agressivo, xingando-a. Em seguida, deu um soco forte no seu ouvido e muitos pontapés".

\section{- Relato 7 - HMMC - Mulher de $\mathbf{3 0}$ anos}

"Relata que estava em casa, brigando com o marido, este deu um soco no seu rosto, ela revidou enfiando uma faca na mão do marido e, como viu que estava sangrando, correu, escorregou e caiu na escada".

Os motivos alegados para desencadear a agressão conjugal variaram em torno de alguns núcleos de sentido básicos: a) o casamento não vai bem (motivos banais do cotidiano que ganham destaque e viram tema de briga, como ligar ou desligar uma TV, manter uma janela aberta); b) a briga é uma rotina (a discussão verbal, acompanhada ou não de agressão física, é uma prática diária do casal); c) estar alcoolizado (o marido alcoolista usualmente ofende e agride fisicamente a mulher); d) meter-se em "negócios de homem" (a mulher cobra satisfações sobre a conduta masculina, como a de olhar para outra mulher, ter amantes, dormir fora de casa e, em um dos casos, por apartar uma briga do marido com outro homem, despertando a sua fúria); e) ele não aceita a separação (separações cuja iniciativa foi feminina e não foram aceitas pelos maridos ou namorados). Naturalmente, estes núcleos não são capazes de exaurir toda a complexidade da temática, são apenas indicativos do conjunto analisado. O ciúme do marido, por exemplo, foi citado em apenas um caso; em 18 casos não foi referido o motivo.

Simão et al. (1997), com base em revisão bibliográfica apontam que em cerca de $50 \%$ das violências contra a mulher, o marido estava alcoolizado. Soares et al. (1996) observaram que $30,3 \%$ dos 521 casos analisados declararam que o seu agressor era alcoólatra ou estava embriagado no momento da agressão. No conjunto dos 71 casos analisados (um caso ignorado), a mulher declarou que algum tipo de droga esteve relacionado em $33,8 \%$ das ocorrências de agressão (24 casos). Esta média mostrou-se muito mais elevada que o conjunto das causa externas atendidas no mesmo período, quando, cerca de $13 \%$, em ambos hospitais, declara- ram o uso de droga como motivo predisponente ou que favoreceu a ocorrência do evento. Obviamente, estes dados não podem ser entendidos como indicadores de uma relação de causalidade direta.

Em alguns relatos, a mulher afirmou não ser a primeira vez que sofre agressão física por parte daquele referido agressor, seja o marido (atual, ex-marido ou namorado), seja parente. Algumas referiram que "não é a primeira vez que é agredida mas não com tal violência" ou que "sempre discutem mas nem sempre há agressão".

Saffioti (1997:155), com base nos dados do IBGE, relata que “ (...) dentre as mulheres vítimas de agressão física, $83 \%$ a sofreram uma única vez, 8\% duas vezes, e 9\% três vezes ou mais".

\section{Atendimento prestado}

A média diária de casos de violência doméstica contra mulheres no HMSF foi de 1,7 e no HMMC foi de 0,7 .

Quanto à hora da entrada da paciente, o plantão diurno ( $8 \mathrm{~h}$ às $20 \mathrm{~h}$ ) recebeu esse tipo de caso com mais freqüência $(59,7 \%)$ que o noturno (de $20 \mathrm{~h} 01 \mathrm{~min}$ às $7 \mathrm{~h} 59 \mathrm{~min}$ ), com $40,3 \%$ dos atendimentos.

O tempo de permanência no setor de emergência ocorreu, predominantemente, num período de uma a seis horas $(60,9 \%)$, seguido daquelas que permaneceram por menos de uma hora $(36,2 \%)$. Do conjunto dos 72 casos, duas mulheres necessitaram internação (uma por espancamento e outra por agressão com arma branca).

O dia da semana em que o atendimento foi realizado aponta, em ordem decrescente, os dias de domingo (24\%), quarta-feira (24\%) e terça-feira (19\%) como os dias mais procurados no HMMC, e segunda-feira (23,5\%), sábado $(19,6 \%)$, domingo $(17,6 \%)$ e quarta-feira (14\%) como os dias mais freqüentes no HMSF. O transporte coletivo foi o meio mais usado $(54,4 \%)$ pelas vítimas para chegar ao hospital, seguido do uso de automóvel (22,1\%). Em três casos, foi necessário o uso de ambulância.

Os especialistas envolvidos no conjunto dos atendimentos podem ser verificados na Figura 1 e apontam o predomínio dos ortopedistas e acadêmicos (neste caso, o atendimento foi realizado sem o acompanhamento de outro profissional formado).

Considerou-se, no aspecto "especialistas envolvidos", a distribuição desses no conjunto dos atendimentos, visando identificar quais as principais especialidades médicas cujos pro- 


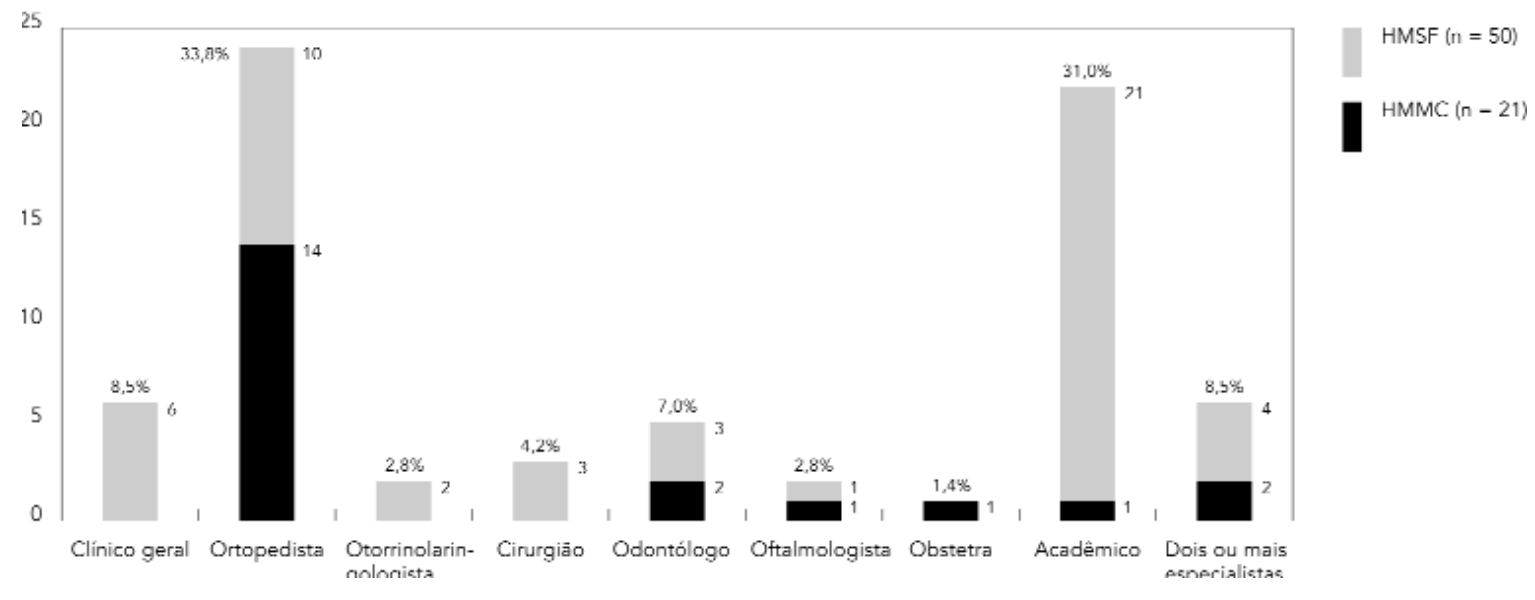

fissionais precisam ser alvo de ações de sensibilização e capacitação frente ao problema da violência doméstica contra a mulher. O presente estudo não dispõe dos diagnósticos para analisar a correção do atendimento frente às necessidades. É sabido, apenas, que ambos hospitais oferecem o mesmo quadro de especialistas. Analisando-se o atendimento prestado pelos dois hospitais, percebe-se que o HMMC envolveu predominantemente o ortopedista $(66,7 \%)$, seguido pelo odontólogo $(9,5 \%)$ e "dois ou mais especialistas" (8,5\%). Comparando-se com o atendimento prestado no conjunto de todas as causa externas, percebe-se que nos atendimentos das mulheres vítimas de violências domésticas houve uma participação muito maior de odontólogos (2,2\% no total das causa externas contra $9,5 \%$ nas violências domésticas) e oftalmologistas (1,6\% contra 4,8\%). No HMSF, o acadêmico foi responsável pela grande maioria dos atendimentos (42\%), seguido pelo ortopedista (20\%). Comparando-se com o conjunto de todas as causa externas atendidas, também percebeu-se uma maior participação de otorrinolaringologistas ( $1 \%$ contra $4 \%$ nos casos de violências domésticas), odontólogos $(3,1 \%$ contra $6 \%)$, oftalmologistas $(1,4 \%$ contra $2 \%$ ). Até mesmo o acadêmico teve uma participação maior nos casos de violências domésticas $(33,9 \%$ no conjunto das causa externas contra $42 \%$ nas violências domésticas).

Das 72 mulheres atendidas, 68 (96\%) tiveram alta, uma foi removida para outro hospi- tal, uma ficou internada (após o término do período de pesquisa) e uma saiu à revelia.

\section{Considerações finais}

O papel das emergências hospitalares para a prevenção de reincidências das violências domésticas é fundamental. A emergência é, via de regra, a porta de entrada e, em muitos casos, o único contato com o sistema de saúde. Se, por um lado, é claro que o atendimento emergencial deve prestar um atendimento clínico e cirúrgico de qualidade, por outro, não pode se restringir ao socorro médico. É preciso discutir o potencial papel de desencadeador de atenção e acompanhamento que o setor de emergência pode representar (Dearwater, 1998). Editorial do American Journal of Public Health discute o problema, deixando claro que as limitações são as mesmas, ou seja, até mesmo em países de economia desenvolvida (mesmo nos Estados Unidos), os casos atendidos nem sempre são registrados e não há um acompanhamento posterior. Percebe-se, inclusive, que a postura dos serviços é diferenciada nos casos de violência contra a mulher, pois, nos casos de abuso contra crianças e nos casos de tentativas de suicídio, a emergência cumpre este papel preventivo (Davidson, 1996).

A relativa disponibilidade que as mulheres agredidas mostraram em relatar o acontecido suscita, por um lado, a oportunidade perdida 
de atuar diante desses casos e, por outro, a surdez das instituições em atender tais apelos.

Segundo os dados analisados, evidenciouse que o atendimento de ortopedistas, odontólogos, oftalmologistas, cirurgiões, otorrinos e clínicos são fundamentais nos casos de violência contra a mulher, visto que a região da face, cabeça, braço e mãos são as áreas mais atingidas, ocasionando fraturas, hematomas e cortes. É necessário ressaltar a importância de sensibilizar esses profissionais para o atendimento desses casos e para a notificação e/ou mobilização de outros profissionais e serviços para o acompanhamento dessas mulheres. As iniciativas de sensibilização do profissional devem também discutir os fatores sociais que constituem o contexto da subnotificação. Como foi discutido, muitas mulheres negam o acontecido, encobrindo seus agressores, por, entre muitos outros motivos, dependerem economicamente deles para seu sustento (nesta pesquisa, a maioria das mulheres era desempregada ou "do lar"). Assim, a própria Organização Panamericana de Saúde (Hartigan, 1997) sugere que o profissional sempre pergunte à mulher (de forma apropriada e nas situações pertinentes) se ela foi vítima de violência doméstica.

Também é importante destacar que, em um atendimento que se proponha a iniciar uma ação protetora e preventiva de reincidências, a presença maciça de acadêmicos, como elemento principal do atendimento, não é a mais adequada, dado que ainda não possuem experiência e articulação institucional suficiente para dar encaminhamento adequado a tais demandas.

\section{Referências}

AZEVEDO, M. A. \& GUERRA, V. N. A., 1989. A Síndrome do Pequeno Poder. São Paulo: Iglu.

BARDIN, L., 1979. Análise de Conteúdo. Lisboa: Edições 70 .

BOULDING, E., 1981. Las mujeres y la violencia social. In: La Violencia y sus Causas (UNESCO, org.), pp. 265-279, Paris: Editorial UNESCO.

CARDOSO, N. M. B., 1996. Mulheres em situação de violência conjugal: incidência, conceitos, fatores associados e conseqüências da violência. Barbarói, 4/5:69-80.

DAVIDSON, L. L., 1996. Preventing injuries from violence towards women. American Journal of Public Health, 86:12-14.

DEARWATER, S. R.; COBEN, J. H.; CAMPBELL, J. C.; NAH, G.; GLASS, N.; McLOUGHLIN, E. \& BEKEMEIER, B. 1998. Prevalence of intimate partner abuse in women treated at community hospital emergency departments. JAMA, 280:433-438.

DESLANDES, S. F., 1997. Relatório Final da Pesquisa "O Impacto da Violência nos Serviços de Emergência Hospitalar". Rio de Janeiro: Centro LatinoAmericano de Estudos de Violência e Saúde Jorge Careli, Departamento de Epidemiologia e Métodos Quantitativos em Saúde, Escola Nacional de Saúde Pública, Fundação Oswaldo Cruz.

FRIEND, J. R., 1998. Responding to violence against women: A specialist's role. Hospital Medicine, 59: 678-679.

GIFFEN, K., 1994. Violência de gênero, sexualidade e saúde. Cadernos de Saúde Pública, 10:146-155.

GOMES, R., 1994. A análise de dados em pesquisa qualitativa. In: Pesquisa Social: Teoria, Método e Criatividade (M. C. S. Minayo, org.), pp. 67-80, Petrópolis: Editora Vozes.

HARTIGAN, P., 1997. La OPS enfoca el problema de la violencia contra la mujer. Revista Panamericana de Salud Pública, 2: 290-294.
HEISE, L.; PITNGUY, J. \& GERMAIN, A., 1994. Violence against Women. The Hidden Health Burden. World Bank Discussion Papers 225. Washington, D.C.: World Bank.

MINAYO, M. C. S. \& SANCHES, O. 1993. Quantitativoqualitativo: Oposição ou complementaridade? Cadernos de Saúde Pública, 9:239-262.

MINAYO, M. C. S.,1992. O Desafio do Conhecimento: Pesquisa Qualitativa em Saúde. São Paulo: Editora Hucitec/Rio de Janeiro: ABRASCO.

MS (Ministério da Saúde), 1993. Violência contra a Criança e o Adolescente. Proposta Preliminar de Prevenção e Assistência à Violência Doméstica. Brasília: Ministério da Saúde.

RODRIGUEZ, J. C. R. \& GUERRA, M. C. P., 1996. Mujeres de Guadalajara y violencia doméstica: Resultados de un estudio piloto. Cadernos de Saúde Pública, 12:405-409.

SAFFIOTI, H. I. B., 1997. No fio da navalha: Violência contra crianças e adolescentes no Brasil atual. In: Quem Mandou Nascer Mulher? Estudos sobre Crianças e Adolescentes Pobres no Brasil (F. R. Madeira, org.), pp. 135-211, Rio de Janeiro: Editora Record/Rosa dos Tempos.

SIMÃO, M. O.; LOUREIRO, S. R.; SMAIRA, S. I. \& KERR-CORRÊA, F., 1997. Alcoolismo feminino: Revisão de aspectos relacionados à violência. $R e$ vista ABP-APAL, 19: 139-148.

SOARES, L. E.; SOARES, B. M. \& CARNEIRO, L. P., 1996. Violência contra a mulher: As DEAMs e os pactos domésticos. In: Violência e Política no Rio de Janeiro (L. E. Soares, org.), pp. 65-106, Rio de Janeiro: Editora Relume-Dumará/ISER.

TUESTA, A. J. A., 1997. Gênero e Violência no Âmbito Doméstico: A Perspectiva dos Profissionais de Saúde. Dissertação de Mestrado, Rio de Janeiro: Escola Nacional de Saúde Pública, Fundação Oswaldo Cruz. 